Manufacturing

\title{
A Monte Carlo framework for managing biological variability in manufacture of autologous cell therapy from mesenchymal stromal cells therapies
}

\author{
Andrew Picken ${ }^{1,3}$, Jon Harriman ${ }^{1,3}$, Andreea Iftimia-Mander ${ }^{2}$, Lyndsey Johnson ${ }^{2}$, \\ Amy Prosser ${ }^{2}$, Robin Quirk ${ }^{2}$, Robert Thomas ${ }^{1,3, *}$ \\ ${ }^{1}$ Centre for Biological Engineering, Holy Well Park, Loughborough University, Loughborough, UK \\ ${ }^{2}$ LocateBio, MediCity, Beeston, UK \\ ${ }^{3}$ Advanced Bioprocess Services, East Leake, Loughborough, UK
}

\section{A R T I C L E I N F O}

Article History:

Received 17 September 2019

Accepted 11 January 2020

\section{Keywords:}

mesenchymal

autologous

Manufacture

process

variability

model

\begin{abstract}
A B S T R A C T
Manufacturing processes for autologous cell therapy need to reproducibly generate in specification (quality and quantity) clinical product. However, patient variability prevents the level of control of cell input material that could be achieved in a cell line or allogeneic-based process. We have applied literature data on bone marrow-derived mesenchymal stromal cells variability to estimate probability distributions for stem cell yields given underlying truncated normal distributions in total nucleated cell concentration, stem cell percentage and plausible aspirate volumes. Monte Carlo simulation identified potential variability in harvested stem cell number in excess of an order of magnitude. The source material variability was used to identify the proportion of donor manufacturing runs that would achieve a target yield specification of 2E7 cells in a fixed time window with given proliferative rates and different aspirate volumes. A rapid, screening, development approach was undertaken to assess culture materials and process parameters (T-flask surface, medium, feed schedule) to specify a protocol with identified proliferative rate and a consequent model-based target aspirate volume. Finally, four engineering runs of the candidate process were conducted and a range of relevant quality parameters measured including expression of markers CD105, CD73, CD44, CD45, CD34, CD11b, CD19, HLA-DR, CD146 (melanoma cell adhesion molecule), CD106 (vascular cell adhesion molecule) and SSEA-4, specific metabolic activity and vascular endothelial growth factor secretion, and osteogenic differentiation potential. Our approach of using estimated distributions from publicly available information provides a route for data-poor earl- stage developers to plan manufacture with defined risk based on rational assumptions; furthermore, the models produced by such assumptions can be used to evaluate candidate processes, and can be incrementally improved with accumulating distribution understanding or subdivision by new process variables.
\end{abstract}

(C) 2020 International Society for Cell and Gene Therapy. Published by Elsevier Inc. This is an open access article under the CC BY license. (http://creativecommons.org/licenses/by/4.0/)

\section{Introduction}

mesenchymal stromal cells (MSCs) are a cell type with a wide range of potential therapeutic applications. Early activity was dominated by orthopedic targets, but significant clinical activity has developed in tissue repair, such as cardiac, and across immunomodulatory targets, such as multiple sclerosis and aging frailty. In addition to acting through direct engraftment, MSCs are considered a potent therapeutic for modulating disease environments through a complex

\footnotetext{
* Correspondence: Robert Thomas, MPharm, PhD, Centre for Biological Engineering, Holy Well Park, Loughborough University, Loughborough, UK, LE11 3AQ.

E-mail address: r.j.thomas@lboro.ac.uk (R. Thomas).
}

bioactive secretome with anti-inflammatory and immunomodulatory properties that interacts beneficially with endogenous repair pathways [1]. MSCs have potential in the treatment of several clinically challenging and hard-to-heal orthopedic indications [2,3]. As a result, a first generation of MSC-containing products (collectively termed "cellular bone matrices") have achieved clinical uptake despite being crudely prepared donor extracts with supply limitations (being harvested from cadavers), variable results and inconclusive clinical outcomes [4]. More advanced orthopedic products involve in vitro expansion of the human bone marrow mesenchymal stromal cells (hBM-MSCs) before combination with a tissue scaffold to ensure that post-implantation viability does not become compromised by anoikis given the attachment dependence of the cells. 
Cell supply issues can potentially be overcome by the pre-implantation expansion of MSCs, with an allogeneic "off-the-shelf" approach finding much support based on the apparent immune privilege of these cells and the attractive regulatory and business model of a standardizable offthe-shelf product [5]. However, there is some literature evidence that allogeneic MSCs may elicit immune responses [6,7], and that rejection of MSCs after differentiation may compromise clinical effectiveness [8]. These risks may be reduced by expansion of the patient's own cells to create autologous 'manufactured' hBM-MSCs. However, such an approach comes with its own challenges of variable starting material and potentially more complex logistics of patient-specific processes and delivery timings. The results of multiple clinical trials show that there have been successes and failures with both approaches; the reasons for inconsistency likely lie in the complexity of heterogenous non-comparable cell populations between trials and inconsistent effects of processing methodologies including variable reagents and preservation methodologies [9]. Both allogeneic and autologous strategies are being actively pursued for near-term clinical application.

As with the cell therapy field in general, the application of MSCbased therapies has been challenged by the variability in processes and products. Conventional pharmaceutical production has made progress over the last decade through adoption of quality risk management strategies developed in other industries, codified in the International Council for Harmonisation Quality Risk Management document Q9 [10]. The ethos of these strategies is science-driven risk assessment. However, although the principles are clear, the effective application of quality risk management strategies for cell therapies requires examples of appropriate tools that deal with the specific issues of the field including variable biological input materials and complex production processes [11]. A bioprocess for the manufacture of a cell therapy needs to be sufficiently robust to the biological variability of the input material to consistently generate cells that meet the required target product profile compatible with current Good Manufacturing Practice. As with any cell therapy, the process is a key determinant of the product, so decisions relating to bioprocess specification and control strategy must be quality risk-managed and supported with enough evidence to satisfy regulatory requirements (as detailed by the International Council for Harmonisation of Technical Requirements for Pharmaceuticals for Human Use in quality guidelines Q8/9).

As noted above, the autologous approach is complicated by significant donor variability [12]. The issue is further compounded in specific patient groups, such as the elderly or those with diabetes, owing to an impaired in vivo niche for BM-MSCs resulting in fewer isolatable BM-MSCs per milliliter bone marrow aspirate and with potential qualitative impairment compared with healthy individuals [13]. Cell therapy manufacturers must manage potential biological variability, or systematic underperformance of autologous cells from the target population with qualitative and quantitative hBM-MSC impairment to avoid unquantified batch failure risk.

Bone marrow aspiration is generally regarded as a safe procedure, however, there are complex and potentially conflicting drivers for specifying aspiration volume for process input material. Excessive aspiration may increase procedural pain [14], whereas insufficient aspiration risks batch failure if not enough BM-MSC yield is achieved post-expansion. Prolonged culture time (consequent on low aspiration cell numbers) elevates risks like microbial contamination during feeding operations, phenotypic drift and commercial risks relating to manufacturing facility throughput and cost of goods. Specification of aspiration volume is further challenged because bone marrow aspiration is a manual process, lacking standardization with respect to materials or sub-processes used. Simple factors like draw volume and syringe volume are reported to influence initial BM-MSC yield per milliliter, with greater draw volumes correlating with lower BMMSC yield per draw, as the aspirate becomes contaminated with peripheral blood [15]. Alongside biological factors like disease state or patient age, process factors including shipping conditions and duration can also result in cell losses post-isolation [16].

This article details the use of a Monte Carlo model to evaluate the effect of variability in BM-MSC isolation from bone marrow aspiration on process outcomes. The model was used to develop a manufacturing framework to manage this variability, increasing the speed and likelihood that a robust manufacturing process would be defined with low risk of batch failure and accommodating logistical process constraints (such as manufacture time). The derived isolation and expansion processes were demonstrated using hBM-MSCs isolated from healthy donors to confirm the validity of the approach. Ultimately, our model is intended to be adjustable to account for any observed impairment of BM-MSC yield and quality from specific patient populations, for well-defined manufacturing and logistical strategies, to maximizing the probability of obtaining a cell therapy product suitable for clinical use from a precious autologous donation.

\section{Methods}

\section{RoosterBio hBM-MSC culture}

A cryovial containing cryopreserved RoosterBio hBM-MSCs (RoosterBio, Inc., Frederick, MD) was thawed in a $37^{\circ} \mathrm{C}$ water bath, washed with RoosterNourish-MSC (RoosterBio, Inc., Frederick, MD) medium and then centrifuged at $200 \mathrm{~g}$ for $5 \mathrm{~min}$. The cell pellet was suspended in fresh RoosterNourish-MSC medium before seeding $5 \mathrm{E} 3 \mathrm{cells} / \mathrm{cm}_{2}$ into an uncoated Nunc T175 flask (Nalge Nunc, Rochester, NY), a Nunc T175 flask coated with $0.2 \mathrm{ng} / \mathrm{cm}^{2}$ fibronectin from human plasma (Sigma-Aldrich, Missouri, USA) and a CellBIND T175 flask (Corning Inc. NY). Flasks were topped up with medium to $35 \mathrm{~mL} /$ flask, then incubated at $37^{\circ} \mathrm{C}$ in a humidified $5 \% \mathrm{CO}_{2}$ in air atmosphere. Medium was exchanged after 2 days before harvesting on day 4 by washing with phosphate-buffered saline (PBS) followed by incubation with $5 \mathrm{~mL}$ TrypLE Select (Gibco, ThermoFischer, Waltham, MA) for $5 \mathrm{~min}$ at $37^{\circ} \mathrm{C}$. Cell detachment was confirmed with light microscopy before addition of medium to quench enzyme activity.

\section{Isolation and culture of $h B M-M S C$ from fresh $h B M$}

Fresh unprocessed bone marrow aspirate obtained with informed consent from healthy human donors was purchased from Lonza (USA) or Caltag Medsystems (UK). Bone marrow aspirate was directly seeded into CellBIND T175 flasks containing either RoosterNourish-MSC medium or Dulbecco's Modified Eagle's medium (DMEM) supplemented with $2 \mathrm{mmol} / \mathrm{L}$ GlutaMAX (Gibco, ThermoFischer, Waltham, MA) and $5 \%$ or $10 \%$ Stemulate Human Platelet Lysate (HPL) (Cook Regentec, Indianapolis, USA). Flasks were topped up to $35 \mathrm{~mL}$ and incubated at $37^{\circ} \mathrm{C}$ in a humidified $4 \% \mathrm{O}_{2}, 5 \% \mathrm{CO}_{2}$ atmosphere. Complete medium exchange was performed at least once every 3 days as a minimum, with three Dulbecco's-PBS washes performed before the first exchange to deplete erythrocytes and non-adhered mononuclear cells.

\section{Cryopreservation and thawing of hBM-MSCs}

Expanded hBM-MSC colonies were harvested by washing with PBS, then incubating with TrypLE Select for up to $10 \mathrm{~min}$ at $37^{\circ} \mathrm{C}$. Cell detachment was confirmed with light microscopy and the cells were diluted with medium to quench enzyme activity before mixing by trituration and transfer into sterile $50-\mathrm{mL}$ centrifuge tubes. Samples were taken for cell counting and viability assessment, and the remaining cell suspension was pelleted using centrifugation at $200 \mathrm{~g}$ for $5 \mathrm{~min}$. The cell pellet was suspended to freezing density of $1 \mathrm{E} 6$ cells $/ \mathrm{mL}$ or $2 \mathrm{E} 6$ cells $/ \mathrm{mL}$ in a freezing medium containing either $2 \%$ or $10 \%$ dimethyl sulfoxide, loaded into 1.8-mL Nunc cryovials with $1 \mathrm{~mL}$ fill volume and allowed to equilibrate at ambient temperature for $10 \mathrm{~min}$. After equilibration, cryovials were loaded into a Via-Freeze Research (Asymptote Ltd, UK) containing a pre- 
chilled $\left(4^{\circ} \mathrm{C}\right)$ sample block. Cryovials were held until the sample block equilibrated back to $4^{\circ} \mathrm{C}$, then a linear ramp was initiated to cool the vials at either $-1^{\circ} \mathrm{C} / \mathrm{min}$ or $-2^{\circ} \mathrm{C} / \mathrm{min}$ to a target temperature of $-80^{\circ} \mathrm{C}$. Frozen cryovials were transferred to long-term storage under liquid nitrogen vapor $\left(<-150^{\circ} \mathrm{C}\right)$ for at least 1 week, until thawing for post-thaw culture analysis. Cryovials containing frozen hBM-MSCs were thawed in a $37^{\circ} \mathrm{C}$ water bath and the contents were diluted with $4 \mathrm{~mL}$ of DMEM supplemented with $10 \%$ Stemulate before centrifugation at $200 \mathrm{~g}$ for $5 \mathrm{~min}$. The resulting supernatants were discarded and the cell pellets suspended into DMEM supplemented with $10 \%$ Stemulate for culture analysis.

\section{Culture analysis}

\section{Cell count and viability}

Bone marrow aspirate samples were analysed using the Viability and Cell Count Blood Assay on a NC-3000 (Chemometec, Denmark) as per the manufacturer's instructions.

Harvested hBM-MSCs were analyzed using the Viability and Cell Count Assay as per the manufacturer's instructions.

\section{Assessment of cell morphology and colony morphology}

Cell morphology and colony morphology were monitored daily during hBM-MSC expansion using light microscopy to inform the decision to proceed to cell harvesting.

\section{Colony-forming assay}

Defined volumes (100 $\mu \mathrm{L}$ to $300 \mu \mathrm{L}$ ) of bone marrow aspirate were carefully seeded into CellBIND T25 flasks containing $5 \mathrm{~mL}$ of growth medium using a pipette. Flasks were fed every 3 days and after 12 days were washed with PBS, fixed using chilled $4 \%$ (wt/vol) paraformaldehyde in PBS at least $30 \mathrm{~min}$ at room temperature. Fixed flasks were stored chilled with parafilm covering until staining with $2 \%$ (wt/vol) toluidine blue in PBS at room temperature for $1 \mathrm{~h}$. Sequential PBS washing was used to de-stain and dyed hBM-MSC colonies ( $>50$ cells) were manually counted with the aid of a light microscope

\section{Surface marker expression using flow cytometry}

Thawed hBM-MSCs were seeded into CellBIND T25 flasks at 5E3 cells/ $\mathrm{cm}^{2}$ and cultured in $5 \mathrm{~mL}$ DMEM $+10 \%$ Stemulate HPL for 4 days, with a medium exchange on day 2 . Harvesting was performed using PBS washing then incubation with $1 \mathrm{~mL}$ TrypLE Select at $37^{\circ} \mathrm{C}$ for $5 \mathrm{~min}$. Cells were centrifuged at $300 \mathrm{~g}$ for $5 \mathrm{~min}$ and resuspended in flow buffer (PBS containing 1\% Bovine Serum Albumin) and mixed with the appropriate volume of antibody, incubated for $30 \mathrm{~min}$ at room temperature, washed once and analyzed using a BD FACSCanto II flow cytometer (BD Biosciences, USA) and gated against specific isotype controls. The antibody panel applied was CD105, CD73, CD44, CD45, CD34, CD11b, CD19, HLA-DR, CD146 melanoma cell adhesion molecule (MCAM), CD106 vascular cell adhesion molecule (VCAM) and Stage specific embryonic antigen 4 (SSEA-4) (all BD Biosciences, USA).

\section{Osteogenic differentiation}

Thawed hBM-MSCs were seeded into Nunc 12-well plates at 1E4 cells $/ \mathrm{cm}^{2}$ and cultured in $0.5 \mathrm{~mL}$ DMEM $+10 \%$ Stemulate HPL growth medium for 2 days. After 2 days, one plate was cultured for an additional $24 \mathrm{~h}$ then sacrificed as an unstained control using $70 \%$ cold ethanol fixation and parafilm storage until staining. A second plate was exchanged with MSCGo Rapid Osteogenic differentiation medium (Biological Industries, Israel) and returned to the incubator for a further 9 to 12 days with medium exchange every 2 to 3 days. Differentiated cells were $70 \%$ ethanol fixed and both undifferentiated and differentiated cells were stained using $2 \%$ alizarin red staining solution to detect calcium mineralization.

\section{Outgrowth analysis}

Thawed hBM-MSCs were seeded into Nunc 6-well plates at 5E3 cells $/ \mathrm{cm}^{2}$ and cultured in $1 \mathrm{~mL}$ DMEM $+10 \%$ Stemulate HPL growth medium for up to 4 days, with a medium exchange on day 2. Plates were sacrificed on days 2, 3 and 4 for spent medium analysis and cell harvesting using PBS washing followed by $0.2 \mathrm{~mL}$ TrypLE Select incubation for $5 \mathrm{~min}$ at $37^{\circ} \mathrm{C}$. Cell detachment was confirmed with light microscopy and enzyme activity was quenched with growth medium, and suspended cells were counted. Cell counts were then used to determine growth kinetics after 2 days post-thaw recovery.

\section{Spent medium analysis}

Glucose, lactate and ammonia concentration in spent medium samples were measured using a Cedex Bioanalyzer HT (Roche CustomBiotech, Germany) as per the manufacturer's instructions. Secreted vascular endothelial growth factor (VEGF) concentration in spent medium was measured using an Invitrogen VEGF enzymelinked immunosorbent assay kit (ThermoFisher Scientific, UK) as per the manufacturers' instructions. Cell-specific production or consumption rates were derived using linear regression of cumulative cell time and concentration.

\section{Monte Carlo simulation of autologous hBM-MSC isolation variability}

The quantity of hBM-MSCs isolated can be defined by the total nucleated cell (TNC) concentration and the percentage of nucleated cells that form colonies on tissue culture plastic with the correct phenotype, multiplied by the total aspirate volume. Data of mean values and standard deviations of TNC per milliliter and the number of hMSCs/mL were taken from Hernigou et al. [15] of 30 healthy human donors, over a wide age range, with no explicit bias in data toward any reported population. Aspirates were taken from multiple independent sites using 10-mL syringes to aspirate $1 \mathrm{~mL}, 2 \mathrm{~mL}, 4 \mathrm{~mL}$ and $10 \mathrm{~mL}$ bone marrow samples from each patient. Figure $1 \mathrm{~A}$ shows how the relationship between TNC density and hBM-MSC density is dependent on the aspirate volume.

A Monte Carlo simulation of bone marrow isolation was made in Excel 2010 (Microsoft, UK). Cumulative normal distributions were generated for total nucleated count (cells/mL), colony-forming units (as a percentage of total nucleated count) and aspirate volume using the Excel normal distribution function (NORMDIST), using mean and standard deviations derived using data from Hernigou et al. [15], shown in Table 1 . Because $1-\mathrm{mL}$ aspirations gave better hBM-MSC yield as a function of TNC (Figure 1A), we derived mean and standard deviation values using the $2 \mathrm{~mL}, 4 \mathrm{~mL}$ and $10 \mathrm{~mL}$ aspiration data to avoid best-case scenarios, which are unlikely to be practical to achieve reliably where several milliliters of aspirate may be required.

A random cumulative probability value ( 0 to 1 ) was generated with the NORMDIST function incorporating the Excel random function $[\operatorname{RAND}()]$, with minimum and maximum values (Table 1 ) applied to randomly generate values from a truncated normal distribution to avoid negative values. The Excel normal distribution inverse function (NORMINV) was then used to return the inverse of the randomly generated cumulative probability value. Total hBM-MSCs from each simulated aspiration were then determined by multiplying total nucleated cells/mL, hBM-MSC fraction (divided by 100 ) and aspirate volume together. Population doubling targets were defined as the binary logarithm of the target hBM-MSC number minus the binary logarithm of the isolated hBM-MSC number.

\section{Results}

Defining the impact of biological input variability on the manufacturing process using Monte Carlo modelling

It is costly and potentially impractical to perform enough bone marrow isolations to gain a statistically robust understanding of the distribution of BM-MSC yield during a resource constrained cell therapy development process. However, this information is necessary to 

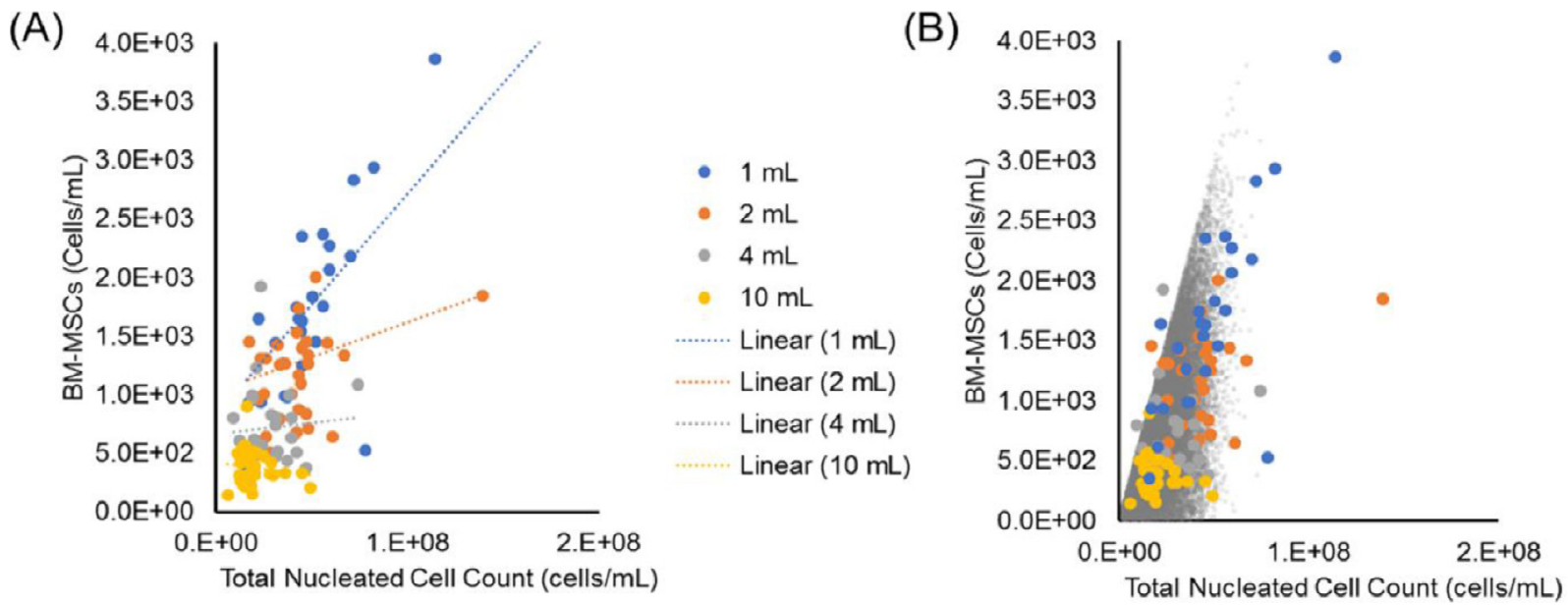

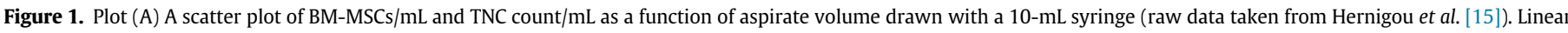

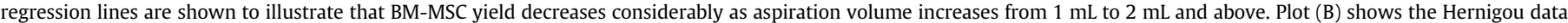
overlaid onto a dot plot of 30000 simulated outcomes using the Monte Carlo model. (Color version of figure is available online).

specify process operation to achieve a given performance. To facilitate rapid process development, we created a model of BM-MSC yield distribution from literature data describing the effects of aspirate volume on target cell concentration, and population variability in target population.

A multi-step Monte Carlo simulation was used to simulate 30000 bone marrow aspirations using the parameters in Table 1. For each simulation, TNCS per milliliter and the fraction of TNC that are hBM-MSCs were independently obtained, and the resulting hBMMSC concentration was calculated. Total hBM-MSCs per aspiration was then obtained by multiplying hBM-MSC concentration with a randomly generated aspirate volume (generated from a target mean of $5 \mathrm{~mL}$, assuming a truncated normal distribution, with a minimum $2 \mathrm{~mL}$ and maximum $12 \mathrm{~mL}$ cut-off). The resulting population of total BM-MSCs per aspirate in 30000 simulated aspirations formed a longtailed distribution (Figure 2A). The number of hBM-MSCs ranged from fewer than 250 to more than 10000 , suggesting a plausible range approaching two orders of magnitude.

Isolated hBM-MSCs need to be expanded in vitro until a target yield is reached that will be specific to a clinical indication. Our yield specification was 2E7 cells (using the exemplar of an autologous cell population intended to be combined with an implantable scaffold material). This target included approximately $50 \%$ overage as an initial estimate of requirements for quality control and assurance testing, and to account for potential losses during cell washing, formulation and cryopreservation.

The 2E7 hBM-MSC yield target informs the number of population doublings needed to meet this process specification given hBM-MSC input from each simulated aspiration. These population doublings create a further distribution representing the variability in required proliferation to hit the target yield if a product developer used all available input material (Figure 2B). Over half (64\%) of the simulated aspirates would need 13 population doublings to meet the harvest target, whereas 16 doublings would be necessary to ensure $>95 \%$ meet the harvest target. The population

Table 1

Monte Carlo model parameters.

\begin{tabular}{llll}
\hline & TNC $($ cells $/ \mathrm{mL})$ & CFU $(\% T N C)$ & Aspirate volume $(\mathrm{mL})$ \\
\hline Min & $2.00 \mathrm{E}+06$ & 0 & 2.5 \\
Max & $8.00 \mathrm{E}+07$ & 0.006 & 12 \\
Avg & $2.39 \mathrm{E}+07$ & 0.003 & 5 \\
SD & $1.18 \mathrm{E}+07$ & 0.002 & 2 \\
\hline
\end{tabular}

CFU, colony-forming unit; Min, minimum; Max, maximum; Avg, average. doubling range defined by the model implies different manufacture times for different inputs posing an operational challenge. A variable manufacture time would complicate logistics, particularly for products that lack a cryopreservation hold step. We, therefore, adopted a strategy of determining a fixed manufacturing window within which an acceptable proportion of material would be estimated to reach the target yield.

Proliferative rate (doubling time) is the final critical parameter determining the cell output in a fixed time window. However, different donors are reported to have different proliferative rates further compounding the variability in quantity of input material. To address this, we evaluated the proportion of simulated aspirates that would meet the 2E7 BM-MSCs harvest target within a 12- to 15-day fixed manufacturing window as a function of both hypothetical doubling time and aspirate volume seeded. Figure 3 shows the proportion of runs predicted to achieve target within a range of 12 to 15 days, as well as those exceeding the yield target before 12 days and those failing to achieve target within 15 days, with seeded aspirate volumes of $6 \mathrm{~mL}, 9 \mathrm{~mL}$ and $12 \mathrm{~mL}$. The peak success rate (cultures achieving target in a 12- to 15-day window) is seen at a different cell doubling time at different aspiration volumes. We would, therefore, want to specify an aspiration volume that had a peak success rate aligned with the average population doubling time in the donor material and expansion process.

Establishing a reasonable window is critical as cultures that grow too rapidly risk exhausting nutrients (e.g., glucose) or production of excessive inhibitory metabolites (e.g., ammonia) given a standardized feeding process targeting the average input. Similarly, cultures which need excessive expansion time to achieve target specification may require passaging if cell motility is insufficient to avoid dense colonies and the emergence of cell aggregates during harvesting. These more extreme cultures that fall outside the manufacturing window may have associated quality issues and could be treated as special cases under risk assessment.

The model outputs highlight the criticality of growth rate when considering the probability of achieving a well-controlled process within a specified manufacturing window. Consequently, the Monte Carlo model enables the specification and benchmarking of acceptable culture parameters (e.g., seeding volume range) to obtain a well-defined culture system compatible with a potentially variable biological input. Defining the process in this way should allow management of hard to control process steps like aspiration (e.g., acceptable aspirate volume ranges) to minimize the chance of wasteful manufacturing deviations due to end harvest number out of specification. 
(A)

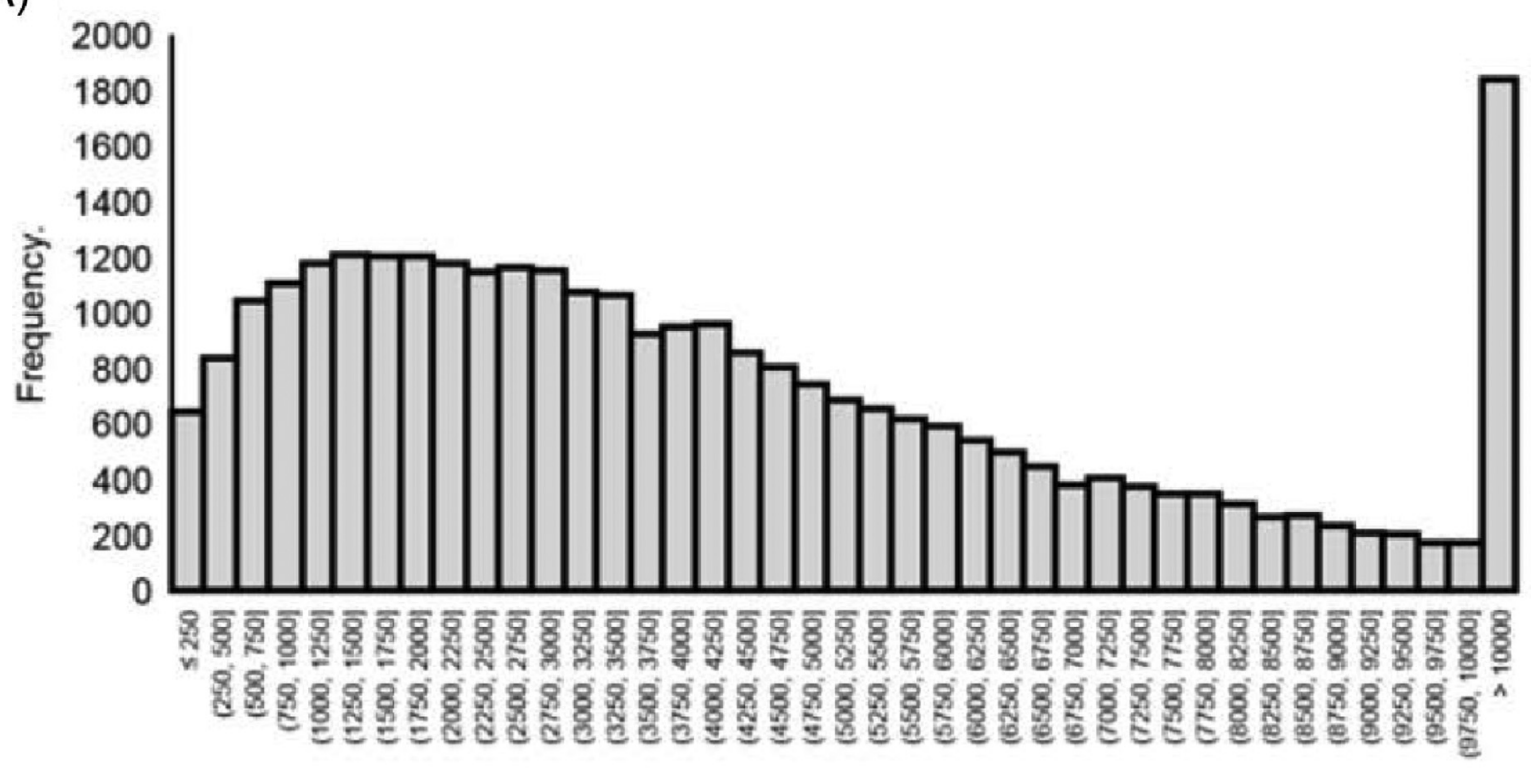

BM-MSC Isolation Yield (Cells)

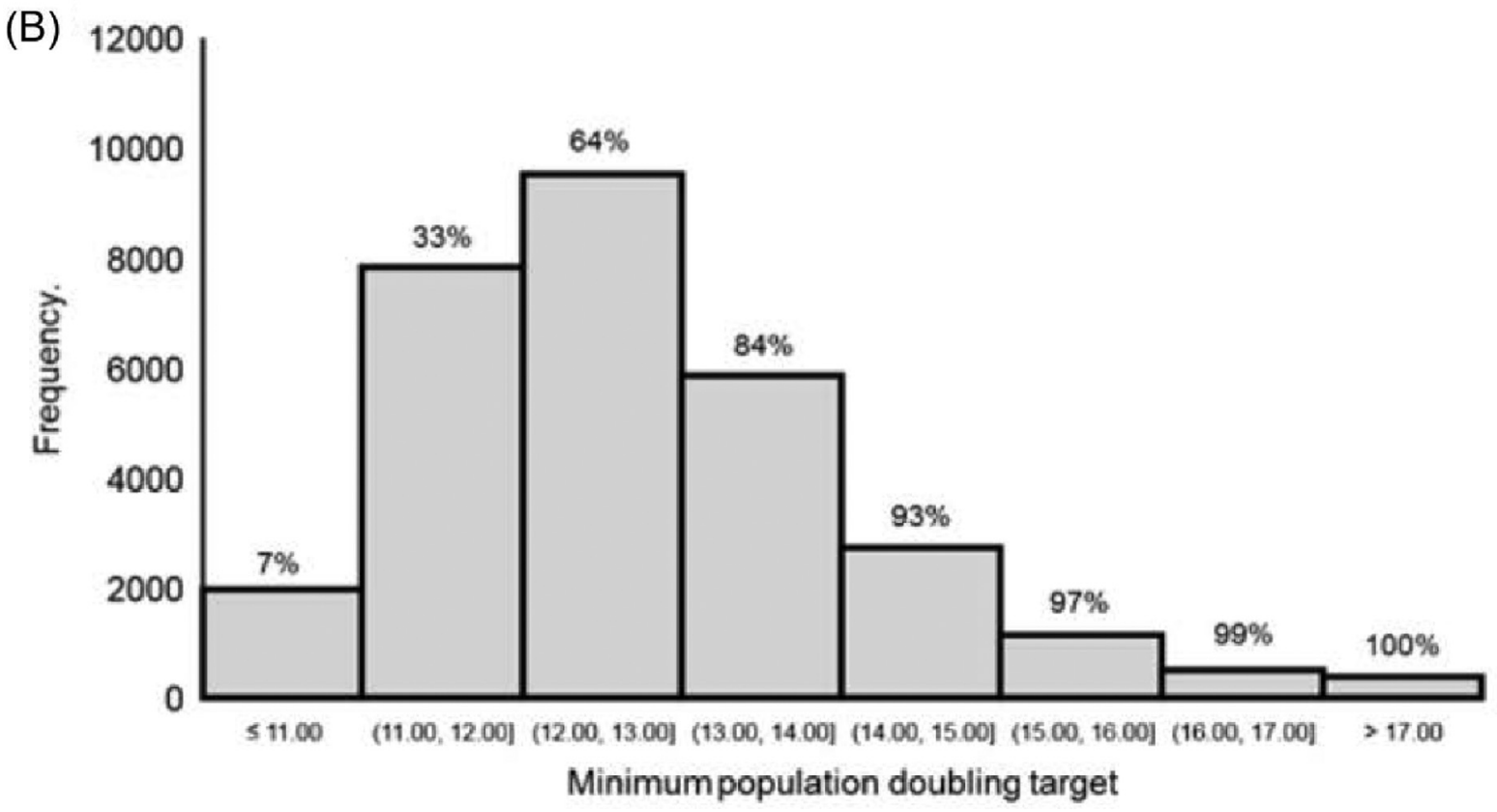

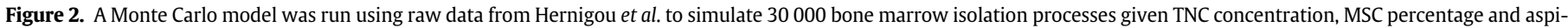

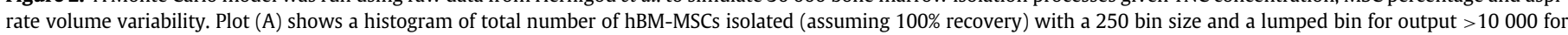
ease of visualization. Plot (B) shows the previous histogram as a function of the minimum number of population doublings needed to obtain $2 \mathrm{E} 7$ cells at harvest.

Establishing a streamlined autologous hBM-MSC manufacturing process using the Monte-Carlo model

Different manufacturing materials and processes are expected to deliver different proliferative rates. We, therefore, screened key variables to establish a process growth rate that would maximize the harvest target to be met within a 15-day manufacturing window (for a given aspirate volume) given the estimations obtained from the Monte Carlo model. First, the impact of culture surface on cell proliferation and harvest density were evaluated. Rooster hMSCs were used in Rooster medium with a 4-day fed-batch expansion on either Corning CellBIND T-flasks, delta-Nunclon treated-flasks or Nunc flasks coated with fibronectin. Rooster hMSCs were chosen for their availability and consistency over fresh bone marrow aspirates for this development step.
Approximately twice as many cells were recovered at harvest (approximately $6 \mathrm{E} 4 / \mathrm{cm}^{2}$ versus $3 \mathrm{E} 4 / \mathrm{cm}^{2}$ ) using CellBIND and fibronectin-coated flasks compared with delta-Nunclon flasks (Figure 4A). Apparent doubling time was shortened from $34 \mathrm{~h}^{-1}$ on delta-Nunclon flasks to $26 \mathrm{~h}^{-1}$ on CellBIND and fibronectin-coated flasks (Figure 4D), with improved membrane integrity (99\% versus $97 \%$ ) on harvest (Figure 4 C). It was also noted that mean cell diameter was smaller in CellBIND flasks compared with cells cultured on delta-Nunclon or fibronectin-coated flasks (Figure 4B). These data suggest CellBIND flasks afford increased headroom for hBM-MSC expansion per centimetre squared of the culture surfaces evaluated, without increasing raw material qualification burden by introducing fibronectin.

After selecting the CellBIND surface for further evaluation, a twostage approach was used to quickly establish a suitable 

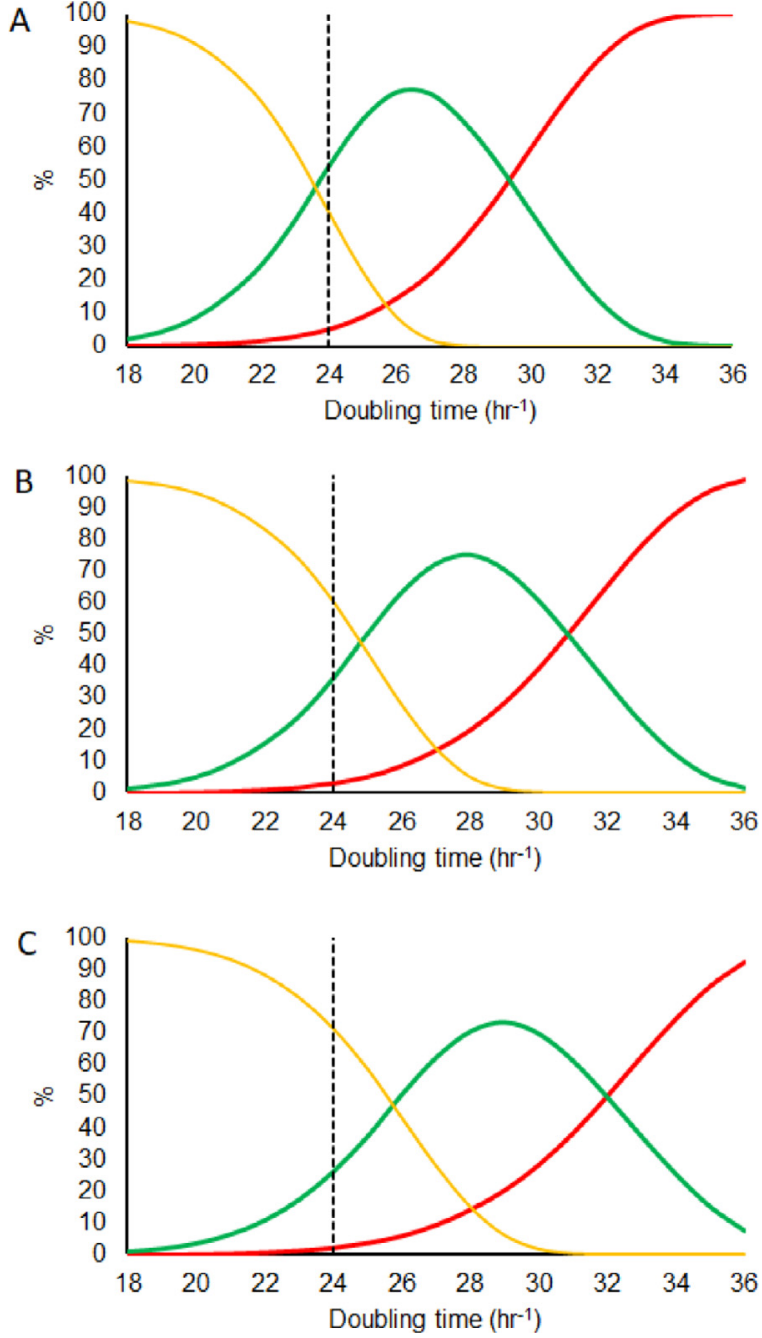

Figure 3. Predicting the proportion of autologous donor inputs that will achieve the target yield (2E7 cells) given different doubling times: (A) $6 \mathrm{~mL}$ bone marrow; (B) $9 \mathrm{~mL}$ bone marrow and (C) $12 \mathrm{~mL}$ bone marrow. Each curve represents the proportion of simulated manufacturing runs that meet target yield within 12-15 days (green curve), meet target before 12 days (orange curve) or fail to meet target within 15 days (red curve), as a function of growth rate. Data generated using predicted population doubling target distribution of 30000 simulated BM-MSC isolation and expansions from bone marrow aspirates (Figure 1). (Color version of figure is available online).

manufacturing process aligned with the Monte Carlo model framework. Two fresh human bone marrow aspirates from healthy donors (LOC18 001 and LOC18 002) were used to confirm the suitability of CellBIND flasks, select an appropriate growth medium and feeding regime, as well as to provide material to scope out a feasible cryopreservation process. The process specified using these studies was then challenged with engineering runs using four different healthy donor bone marrow aspirates from two different suppliers (LOC18 003, 004, 005 and 006), according to standard operating procedures and data recorded in line with that required for a draft manufacturing batch record.

Adherent cells with BM-MSC morphology were successfully isolated and expanded as colonies from $3 \mathrm{~mL}$ LOC18 001 aspirate directly plated into CellBIND flasks containing DMEM supplemented with $10 \%$ or $5 \%$ Stemulate. In contrast, no colonies were isolated from LOC18 001 aspirate when using RoosterNourish medium, with no BM-MSCs visible by microscopy after the first wash and medium exchange (Table 2).

DMEM-Stemulate culture in CellBind flasks supported more than 12 population doublings during a 14-day expansion under hypoxic $\left(4 \% \mathrm{O}_{2}\right)$ growth conditions (Table 2). Doubling time was $25.4 \mathrm{~h}^{-1}$ with $10 \%$ Stemulate supplementation (Table 2), consistent with the doubling times previously established for Rooster hMSCs on CellBIND flasks in RoosterNourish medium (Figure 4D). Around 220 hBM-MSC colony forming units per $\mathrm{mL}$ aspirate were isolated, which would satisfy the 2E7 BM-MSC harvest target within 15 days if at least $6 \mathrm{~mL}$ were seeded into three T175 flasks. Doubling time was maintained over serial passaging, with retention of expected cell morphology for at least 20 in vitro population doublings under hypoxic $\left(4 \% \mathrm{O}_{2}\right)$ culture conditions suggesting substantial proliferative headroom (Figure 5A).

A customs delay for the second donor (LOC18 002) resulting in a 72-h shipping period, with noticeable evidence of clotting in the aspirate on visual inspection. Consequently, a higher seeding volume (4 $\mathrm{mL}$ ) was used to compensate for presumed loss of hBM-MSC yield. Adherent cells with hBM-MSC morphology were also isolated and expanded as colonies from $4 \mathrm{~mL}$ LOC18 002 aspirate directly plated into CellBIND flasks supplemented with $10 \%$ Stemulate. While this donor contained fewer colony-forming units than the first (71 versus 220 ), over 15 population doublings occurred during a 15-day expansion ( $22 \mathrm{~h}^{-1}$ to $24 \mathrm{~h}^{-1}$ doubling times), resulting in enough cells in all three flasks to meet the 2E7 harvest target (Table 2). A feed $24 \mathrm{~h}$ post-seeding followed by a 3-day feed cycle without a wash was acceptable and supported cell growth to confluence in excess of other strategies ( $>6 \mathrm{E} 4 \mathrm{cells} / \mathrm{cm}^{2}$ ). Doubling times were also stable over 30 populations doublings during serial passaging (Figure 5B).

The successful isolation and expansion of hBM-MSCs from both donors established the suitability of both CellBIND flasks and Stemulate-supplemented DMEM fed on a 3-day feeding cycle for our candidate manufacturing protocol. The observed doubling times of between 22 and 26 h would translate into more than $95 \%$ of runs successfully meeting the harvest target within the 15-day manufacturing window for an aspirate seeding volume range of $9 \mathrm{~mL}$ to $12 \mathrm{~mL}$.

Both pre-engineering run donor hBM-MSCs were successfully harvested, cryopreserved, thawed and expanded with assessment of a range of hMSC quality criteria (data summarized in Table 3). A screening evaluation of faster cooling rates $\left(-2^{\circ} \mathrm{C} / \mathrm{min}\right)$ and lower Dimethyl Sulfoxide (DMSO) concentration (2\%) were associated with greater cell loss post-thaw. However, hBM-MSCs were still recoverable, with thawed cells maintaining proliferative potential with comparable doubling times to that observed pre-freeze. Candidate quality criteria were assessed on thawed cells including secreted VEGF and consumed glucose and secreted lactate (with a 1.7 stoichiometry observed). Furthermore, after 4 days of post-thaw expansion, harvested cells displayed surface marker expression profiles consistent with the International Society for Cellular Therapy (ISCT) criteria [17], with $>95 \%$ expression of CD105, CD73 and CD44 and $<2 \%$ expression of CD45, CD34, CD11b, CD19 and HLA-DR (Table 2). Isolated BM-MSC cultures also displayed appropriate morphology and exhibited >95\% expression of CD146 (MCAM), <23\% CD106 (VCAM) expression and 16-20\% SSEA-4 expression (Table 3). Finally, the harvested cells were able to differentiate down an osteogenic lineage as demonstrated by calcium mineral deposition in osteogenic differentiation medium.

These results establish that direct plating of between $9 \mathrm{~mL}$ and $12 \mathrm{~mL}$ of bone marrow aspirate into 3x T175 CellBIND flasks containing DMEM + 10\% Stemulate will isolate hBM-MSCs. A 3-day feed cycle will allow hBM-MSC outgrowth with doubling times between $22 \mathrm{~h}^{-1}$ and $26 \mathrm{~h}^{-1}$, which provides an initial base case prediction that sufficient cryopreservable hBM-MSCs to exceed a 2E7 harvest target within a 15-day manufacturing window will be generated for more than $95 \%$ of patients based on the Monte Carlo model.

\section{Confirming suitability of the streamlined hBM-MSC manufacturing} process with fresh donor aspirates

To confirm that the streamlined hBM-MSC manufacturing process was fit for purpose, we conducted four engineering runs of the 

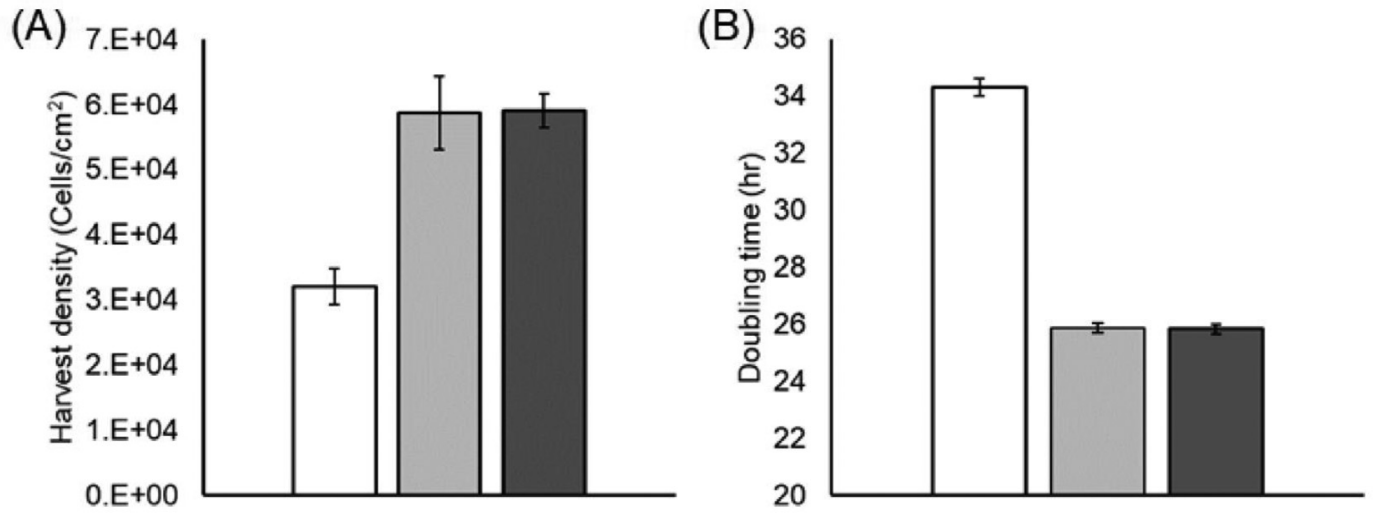

(C)

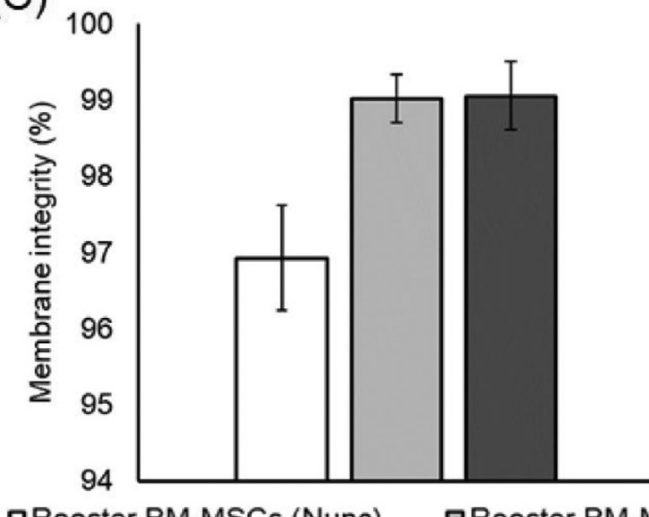

(D)

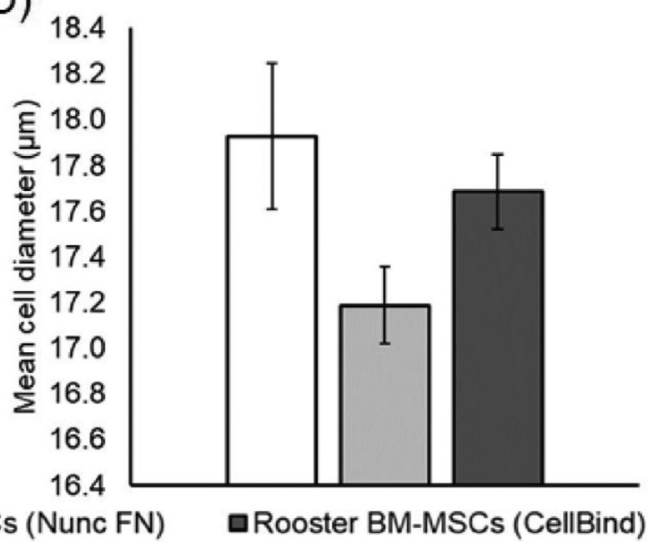

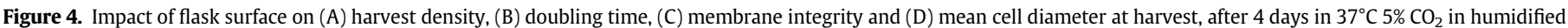
air. Nunc FN = fibronectin-coated.

Table 2

Experimental isolation and expansion of BM-MSCs from LOC18 001 and LOC18 002 bone marrow aspirates.

\begin{tabular}{|c|c|c|c|c|c|c|c|}
\hline \multirow[b]{2}{*}{ Parameter } & \multirow[b]{2}{*}{ Process stage } & \multicolumn{6}{|c|}{ Donor ID (experimental runs) } \\
\hline & & \multicolumn{3}{|c|}{ LOC18 001} & \multicolumn{3}{|c|}{ LOC18 002} \\
\hline $\begin{array}{l}\text { Bone marrow TNC count } \\
\text { (cells } / \mathrm{mL} \text { ) }\end{array}$ & Post-isolation & \multicolumn{3}{|c|}{$1.50 \mathrm{E}+07$} & \multicolumn{3}{|c|}{$2.70 \mathrm{E}+07$} \\
\hline $\begin{array}{l}\text { Bone marrow TNC count } \\
\text { (cells } / \mathrm{mL} \text { ) }\end{array}$ & Post-shipment & \multicolumn{3}{|c|}{$1.12 \mathrm{E}+07$} & \multicolumn{3}{|c|}{$1.68 \mathrm{E}+07$} \\
\hline TNC recovery (\%) & Post-shipment & \multicolumn{3}{|c|}{74.67} & \multicolumn{3}{|c|}{62.22} \\
\hline Shipment duration (h) & Post-shipment & \multicolumn{3}{|c|}{$<48$} & \multicolumn{3}{|c|}{$<72$} \\
\hline $\begin{array}{l}\text { Bone marrow TNC mem- } \\
\text { brane integrity (\%) }\end{array}$ & Post-shipment & \multicolumn{3}{|c|}{98} & \multicolumn{3}{|c|}{90} \\
\hline $\begin{array}{l}\text { BMA seeding volume } \\
(\mathrm{mL})\end{array}$ & BM-MSC expansion & 3 & 3 & 3 & 4 & 4 & 4 \\
\hline Culture duration (d) & BM-MSC expansion & \multicolumn{3}{|c|}{14} & \multicolumn{3}{|c|}{15} \\
\hline Culture vessel & BM-MSC expansion & $1 \times$ T175 (CellBind) & 1 x T175 (CellBind) & 1 x T175 (CellBind) & $1 \times$ x 175 (CellBind) & $\begin{array}{l}1 \times \text { x175 } \\
\text { (CellBind) }\end{array}$ & $\begin{array}{l}1 \times \mathrm{T} 175 \\
\text { (CellBind) }\end{array}$ \\
\hline Culture medium & BM-MSC expansion & $\begin{array}{l}\text { RoosterNourish- } \\
\text { MSC }\end{array}$ & $\begin{array}{l}\text { DMEM + 5\% Stemu- } \\
\text { late HPL }\end{array}$ & $\begin{array}{c}\text { DMEM + } 10 \% \text { Ste- } \\
\text { mulate HPL }\end{array}$ & \multicolumn{3}{|c|}{ DMEM + $10 \%$ Stemulate HPL } \\
\hline Feeding strategy & BM-MSC expansion & \multicolumn{3}{|c|}{$100 \%$ exchange after $1 \mathrm{~d}$, then every $3 \mathrm{~d}$} & $\begin{array}{r}100 \% \text { exchange after } \\
1 \mathrm{~d} \text {, then every } 3 \mathrm{~d}\end{array}$ & $\begin{array}{l}100 \% \text { exchange } \\
\text { after } 1 \mathrm{~d} \text {, then } \\
\text { every } 2 \mathrm{~d}\end{array}$ & $\begin{array}{c}100 \% \text { exchange } \\
\text { every } 3 \mathrm{~d}\end{array}$ \\
\hline $\mathrm{O}_{2}(\%)$ & BM-MSC expansion & \multicolumn{3}{|c|}{4} & \multicolumn{3}{|c|}{4} \\
\hline $\mathrm{CO}_{2}(\%)$ & BM-MSC expansion & \multicolumn{3}{|c|}{5} & \multicolumn{3}{|c|}{5} \\
\hline Temperature $\left({ }^{\circ} \mathrm{C}\right)$ & BM-MSC expansion & \multicolumn{3}{|c|}{37} & \multicolumn{3}{|c|}{37} \\
\hline $\begin{array}{l}\text { BM-MSC CFU-F (colo- } \\
\text { nies/mL) }\end{array}$ & BM-MSC harvest & 0 (failure to adhere) & 224 & 220 & \multicolumn{3}{|c|}{71.1} \\
\hline $\begin{array}{l}\text { BM-MSC seeding den- } \\
\text { sity }\left(\text { cells } / \mathrm{cm}^{2}\right)\end{array}$ & BM-MSC harvest & ND & 3.84 & 3.77 & \multicolumn{3}{|c|}{1.63} \\
\hline Harvest yield (cells $/ \mathrm{cm}^{2}$ ) & BM-MSC harvest & 0 & $1.71 \mathrm{E}+04$ & $3.72 \mathrm{E}+04$ & $3.33 \mathrm{E}+04$ & $4.79 \mathrm{E}+04$ & $6.30 \mathrm{E}+04$ \\
\hline $\begin{array}{l}\text { Harvest yield (viable } \\
\text { cells/flask) }\end{array}$ & BM-MSC harvest & 0 & $2.99 \mathrm{E}+06$ & $6.50 \mathrm{E}+06$ & $5.83 \mathrm{E}+06$ & $8.38 \mathrm{E}+06$ & $1.10 \mathrm{E}+07$ \\
\hline $\begin{array}{l}\text { BM-MSC membrane } \\
\text { integrity (\%) }\end{array}$ & BM-MSC harvest & 0 & 94.3 & 96.5 & 96.4 & 94.8 & 96.8 \\
\hline Population doublings & BM-MSC harvest & ND & 12.13 & 13.25 & 15.34 & 15.9 & 16.32 \\
\hline Doubling time $(\mathrm{h})$ & BM-MSC harvest & ND & 27.7 & 25.4 & 23.47 & 22.64 & 22.06 \\
\hline
\end{tabular}

ND, Not Detected. 
(A)

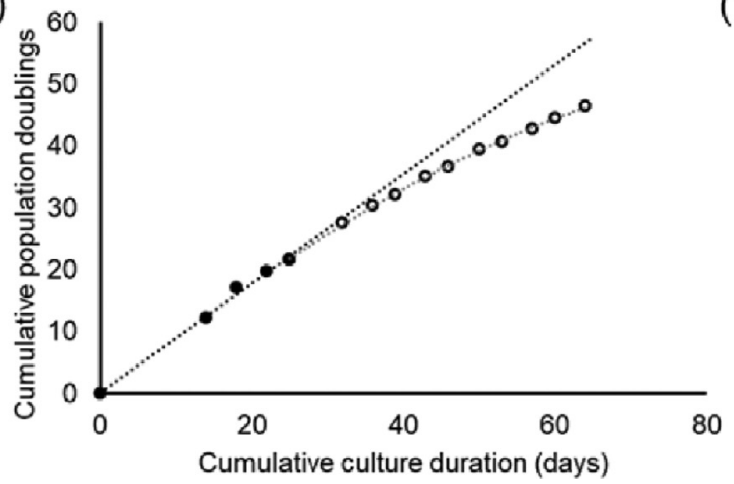

(B)

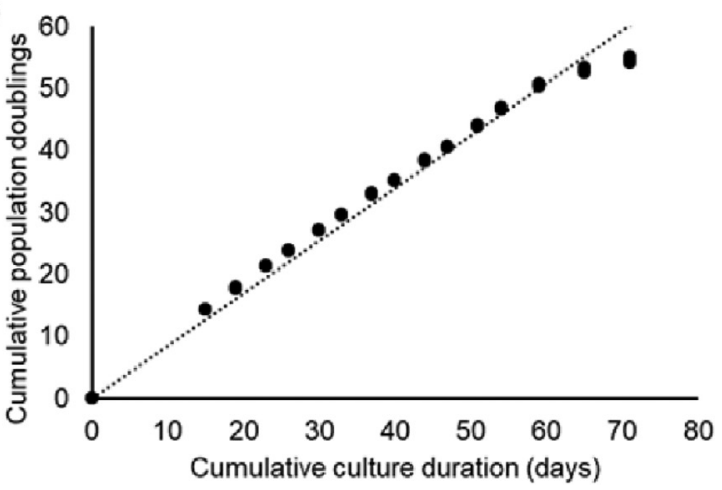

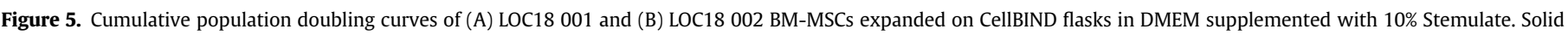
circles indicate data used for regression.

process with fresh bone marrow aspirates from two different suppliers. The process was run according to standard operating procedures and documented using draft manufacturing batch records.

For two bone marrow aspirate donor lots (Lonza), three T175 flasks were seeded for $4 \mathrm{~mL}$ of bone marrow aspirate each $(12 \mathrm{~mL}$ total) and cultured for 12 days. For the remaining two bone marrow aspirate donor lots (Caltag Medsystems), three T175 flasks were seeded with $3 \mathrm{~mL}$ of bone marrow aspirate ( $9 \mathrm{~mL}$ total) and cultured for 15 days. All aspirates were shipped within $48 \mathrm{~h}$ of collection, with at least $75 \%$ of the expected number of nucleated cells counted on receipt (Table 4). Furthermore, membrane integrity was $>90 \%$ in all cases, with no visible indication of clotting in any of the aspirates.

As expected, differences in isolatable colony-forming units were observed between the donor bone marrow aspirates (range, 50-400 colony-forming units $/ \mathrm{mL}$ ). Despite this variability, all engineering runs achieved the harvest target of $>2$ E7 cells within a 15-day limit, with doubling times between 22 and $26 \mathrm{~h}$ (Table 3). The doubling times observed were comparable with the two development runs using DMEM+10\% Stemulate on CellBIND flasks (Table 2).

Harvested hBM-MSCs from each run were successfully cryopreserved using $10 \%$ DMSO and $-1{ }^{\circ} \mathrm{C} /$ min cooling protocol, with $>75 \%$ intact cells recovered post-thaw (Table 5). Post-thaw expansion was demonstrated in each case, with doubling times (21 to $24 \mathrm{~h}$ ) comparable or better than pre-freeze values (Table 5).

Each donor varied in terms of glucose consumption and lactate production during post-thaw expansion, with stoichiometries ranging from 1.8 to 2.4 (Table 5). However, net fluxes were consistent with expectation (range $16 \mathrm{pmol} / \mathrm{cell}^{-\mathrm{d}^{-1}}$ to $26 \mathrm{pmol} / \mathrm{cell}^{-\mathrm{d}^{-1}}$ ) for actively proliferating hBM-MSCs [18,19].

Population identity and purity was determined by surface marker expression according to ISCT minimal criteria [17], with cells displaying $>95 \% \mathrm{CD} 90 / \mathrm{CD} 105 / \mathrm{CD} 77 / \mathrm{CD} 44$ and $<5 \%$ CD45/CD34/CD11b/ CD19/HLA-DR. Expression of CD146 (>90\%), CD106 (2-22\%) and SSEA4 (35-55\%) was also detected in the population, albeit in a donor-dependent manner (Table 5). The relevance of the cells isolated from bone marrow for spinal fusion repair was also established by confirming VEGF secretion capability (range $5.5 \mathrm{fg} / \mathrm{cell}^{-d a y}{ }^{-1}$ to $16 \mathrm{fg} /$ cell.day $^{-1}$ ) and osteogenic differentiation capability (Table 5).

\section{Discussion}

Donor and aspiration process variability complicates the specification of bone marrow aspiration volume from patients for robust manufacture of cell therapy treatments. We sought to use published information on donor variability and stem cell isolation to facilitate statistically informed decision-making during bioprocess design given the limited donor data available in a constrained development window. The objective was to generate a cell expansion process capable of achieving therapeutic cell doses with defined risk of failure accommodating potential logistical constraints such as a target manufacturing window.

We leveraged literature data on bone marrow isolation under defined conditions, to model the consequences of donor variability on relevant bioprocess parameters using a Monte Carlo approach. Within the model boundaries, isolated cell number ranged over four orders of magnitude, requiring up to 17 population doublings to hit harvest target in $99 \%$ of cases. Culture time to achieve harvest target is sensitive to mean doubling time, aspirate volume and the underlying cell isolation density distribution obtained from the Monte Carlo model. Increasing aspirate seeding volume from $6 \mathrm{~mL}$ to $12 \mathrm{~mL}$ was only marginally effective in lowering the risk of failure to meet harvest target (assuming a 15-day manufacturing limit imposed for operability reasons). Instead, the model output indicated that a culture system capable of sustaining population doubling times of approximately $26 \mathrm{~h}$ or less is important to minimise failure risk $<5 \%$.

Rooster hMSCs were used to evaluate culture surface coatings, with Corning CellBIND flasks being selected over Nunclon-Delta or fibronectin-coated flasks, based on doubling rate $\left(26 \mathrm{~h}^{-1}\right)$ and maximal cells/ $\mathrm{cm}^{2}$ at harvest. Although Rooster hMSCs are recognized to have differences to fresh hMSCs from healthy donors, their ability to proliferate rapidly and cell size distribution were considered a reasonable enough proxy to scope out cell surface utilization and aid the initial specification of culture surface area requirements to be evaluated with fresh human bone marrow aspirate from healthy donors, given the final process would be validated with fresh cells. Two fresh human bone marrow aspirates were used to confirm the suitability of CellBIND flasks, to establish the suitability of Stemulate platelet lysate as a medium supplement with a reasonable feeding strategy, to establish a cryopreservation process and to establish analytics suitable for in-process monitoring and a specification for release of cryopreserved cells for bone regeneration (e.g., VEGF secretion) [20] as an exemplar therapeutic application to contextualize cell quality. Finally, we conducted four engineering runs with fresh human bone marrow aspirate following the process established with the aid of the Monte Carlo modelling. These all fell within specification as expected and within the 15-day manufacturing window with doubling times $<26 \mathrm{~h}^{-1}$.

Monte Carlo methods have been applied in several different fields to understand probability of outcomes where prediction is difficult due to stochastic properties of the modelled system. Consequently, they are well suited for the prediction of cell isolation where sufficient data exists of underlying statistical distributions. Establishing an understanding of the risks donor cell supply can have on bioprocess design and operational risks is crucial if the resulting bioprocess is to be robust. The Monte Carlo approach quickly enables risk-based decision-making for bioprocess parameter setting during development. Commercial considerations, such as fixed manufacturing window, are important for delivery of a successful therapeutic product. Manufacturing throughput ultimately imposes restrictions on how 
Table 3

Cryopreservation, post-thaw expansion and quality attributes of BM-MSCs isolated from LOC18 001 and LOC18 002 bone marrow aspirates.

\begin{tabular}{|c|c|c|c|c|c|c|c|c|c|}
\hline \multirow{3}{*}{$\begin{array}{l}\text { Parameter } \\
\text { Culture medium }\end{array}$} & \multirow{3}{*}{$\begin{array}{l}\text { Process stage } \\
\text { BM-MSC expansion }\end{array}$} & \multicolumn{8}{|c|}{ Experimental runs } \\
\hline & & \multicolumn{6}{|c|}{ LOC18 001} & \multicolumn{2}{|c|}{ LOC18 002} \\
\hline & & \multicolumn{2}{|c|}{ DMEM + 10\% Stemulate HPL } & \multicolumn{2}{|c|}{ DMEM + 10\% Stemulate HPL } & \multicolumn{2}{|c|}{ DMEM + 5\% Stemulate HPL } & \multirow{2}{*}{$\begin{array}{l}\text { DMEM + 10\% Stemulate HPL } \\
1.00 \mathrm{E}+06\end{array}$} & \multirow{2}{*}{$\begin{array}{l}\text { DMEM + 10\% Stemulate HPL } \\
1.00 \mathrm{E}+06\end{array}$} \\
\hline BM-MSCs (cells/vial) & Cryopreservation & $1.00 \mathrm{E}+06$ & & $1 \mathrm{E}+06$ & & $1 \mathrm{E}+06$ & & & \\
\hline DMSO (\%) & Cryopreservation & 2 & & 10 & & 10 & & 10 & 2 \\
\hline Cooling rate $\left(-{ }^{\circ} \mathrm{C} / \mathrm{min}\right)$ & Cryopreservation & 1 & & 1 & & 1 & & 2 & 2 \\
\hline Vials & Cryopreservation & 1 & 1 & 1 & 1 & 1 & 1 & 6 & 6 \\
\hline BM-MSCs (cells/vial) & Post-thaw & $7.33 \mathrm{E}+05$ & $1.01 \mathrm{E}+06$ & $9.42 \mathrm{E}+05$ & $9.82 \mathrm{E}+05$ & $9.14 \mathrm{E}+05$ & $8.51 \mathrm{E}+05$ & $4.64 \mathrm{E}+05$ & $8.24 \mathrm{E}+05$ \\
\hline BM-MSC membrane integrity (\%) & Post-thaw & 87.7 & 83.7 & 93.3 & 92.0 & 91.86 & 90.25 & 73.57 & 79.66 \\
\hline Viable cell recovery (\%) & Post-thaw & 64.28 & 84.54 & 87.85 & 90.35 & 83.96 & 76.80 & 34.11 & 65.67 \\
\hline P1 culture duration (days) & Post-thaw outgrowth & 4 & & 4 & & 4 & & 4 & 4 \\
\hline Culture medium & Post-thaw outgrowth & DMEM + 1 & Stemulate HPL & DMEM + & Stemulate HPL & DMEM + & Stemulate HPL & DMEM + $10 \%$ Stemulate HPL & DMEM + $10 \%$ Stemulate HPL \\
\hline Feeding strategy & Post-thaw outgrowth & No feed & Fed d 2 & No feed & Fed d 2 & No feed & Fed d 2 & Fed d 2 & Fed d 2 \\
\hline Population doublings & Post-thaw outgrowth & 2.31 & 3.25 & 2.83 & 3.20 & 3.01 & 3.03 & 3.38 & 3.01 \\
\hline Doubling time $(\mathrm{h})$ & Post-thaw outgrowth & 31.20 & 20.90 & 25.47 & 21.25 & 23.90 & 21.74 & 20.52 & 23.08 \\
\hline Cell-specific glucose consumption (pmo/cell.day ${ }^{-1}$ ) & Post-thaw outgrowth & 25.84 & ND & 24.31 & ND & 24.42 & ND & 20.87 & 22.13 \\
\hline Cell-specific lactate production (pmol/cell.day ${ }^{-1}$ ) & Post-thaw outgrowth & 45.39 & ND & 42.66 & ND & 41.50 & ND & 45.01 & 42.13 \\
\hline qLactate/qGlucose & Post-thaw outgrowth & 1.76 & ND & 1.76 & ND & 1.70 & ND & 2.16 & 1.90 \\
\hline Cell-specific ammonia production (pmol/cell.day ${ }^{-1}$ ) & Post-thaw outgrowth & 4.59 & ND & 3.98 & ND & 3.01 & ND & 9.13 & 3.24 \\
\hline BM-MSC membrane integrity (\%) & Post-thaw harvest & 95.50 & 98.80 & 98.30 & 98.40 & 96.00 & 97.90 & 98.79 & 99.63 \\
\hline CD90 (FITC) (\%) & Post-thaw harvest & ND & & 98.35 & & ND & & ND & 99.98 \\
\hline CD105 (PerCP-Cy ${ }^{\mathrm{TM}} 5.5$ ) (\%) & Post-thaw harvest & ND & & 99.8 & & ND & & ND & 99.45 \\
\hline CD73 (APC) (\%) & Post-thaw harvest & ND & & 99.95 & & ND & & ND & 99.98 \\
\hline CD45/CD34/CD11b/CD19/HLA-DR (PE) (\%) & Post-thaw harvest & ND & & 1.67 & & ND & & ND & 1.13 \\
\hline CD44 (PE) (\%) & Post-thaw harvest & ND & & 99.62 & & ND & & ND & 92.85 \\
\hline SSEA-4 (PE) (\%) & Post-thaw harvest & ND & & 21.49 & & ND & & ND & 16.28 \\
\hline CD106 (VCAM) (PerCP-Cy $\left.{ }^{\mathrm{TM}} 5.5\right)(\%)$ & Post-thaw harvest & ND & & 4.68 & & ND & & ND & 23.03 \\
\hline CD146 (MCAM) (APC) (\%) & Post-thaw harvest & ND & & 95.63 & & ND & & ND & 95.4 \\
\hline VEGF (fg/cell.day $\left.{ }^{-1}\right)$ & Post-thaw harvest & 18.47 & & 16.43 & & 15.96 & & 4.25 & 6.87 \\
\hline Osteogenic differentiation (alizarin red stained) & Post-differentiation & Pass & & Pass & & Pass & & Pass & Pass \\
\hline
\end{tabular}


Table 4

Verification of BM-MSC isolation and expansion process.

\begin{tabular}{|c|c|c|c|c|c|}
\hline \multirow[b]{2}{*}{ Parameter } & \multirow[b]{2}{*}{ Process stage } & \multicolumn{4}{|c|}{ Donor ID (verification runs) } \\
\hline & & LOC18 003 & LOC18 004 & LOC18 005 & LOC18 006 \\
\hline Bone marrow TNC count (cells/mL) & Post-isolation & $3.62 \mathrm{E}+07$ & $2.39 \mathrm{E}+07$ & $1.49 \mathrm{E}+07$ & $8.26 \mathrm{E}+06$ \\
\hline Bone marrow TNC count (cells/mL) & Post-shipment & $2.96 \mathrm{E}+07$ & $2.30 \mathrm{E}+07$ & $1.11 \mathrm{E}+07$ & $6.59 \mathrm{E}+06$ \\
\hline TNC recovery (\%) & Post-shipment & 81.77 & 96.23 & 74.50 & 79.78 \\
\hline Shipment duration (h) & Post-shipment & $<48$ & $<48$ & $<48$ & $<48$ \\
\hline $\begin{array}{l}\text { Bone marrow TNC membrane } \\
\text { integrity (\%) }\end{array}$ & Post-shipment & 97 & 97.4 & 97.8 & 93.5 \\
\hline BMA seeding volume $(\mathrm{mL})$ & BM-MSC expansion & 12 & 12 & 9 & 9 \\
\hline Culture duration $(\mathrm{d})$ & BM-MSC expansion & 12 & 12 & 15 & 15 \\
\hline Culture vessel & BM-MSC expansion & $3 \times$ T175 (CellBind) & $3 \times$ T175 (CellBind) & $3 \times \mathrm{T} 175$ (CellBind) & $3 \times \mathrm{T} 175$ (CellBind) \\
\hline Culture medium & BM-MSC expansion & DMEM + 10\% Stemulate HPL & DMEM + 10\% Stemulate HPL & DMEM + 10\% Stemulate HPL & DMEM + $10 \%$ Stemulate HPL \\
\hline Feeding strategy & BM-MSC expansion & $100 \%$ exchange every $3 d$ & $100 \%$ exchange every $3 \mathrm{~d}$ & $100 \%$ exchange every $3 \mathrm{~d}$ & $100 \%$ exchange every $3 \mathrm{~d}$ \\
\hline $\mathrm{O}_{2}(\%)$ & BM-MSC expansion & 4 & 4 & 4 & 4 \\
\hline $\mathrm{CO}_{2}(\%)$ & BM-MSC expansion & 5 & 5 & 5 & 5 \\
\hline Temperature $\left({ }^{\circ} \mathrm{C}\right)$ & BM-MSC expansion & 37 & 37 & 37 & 37 \\
\hline BM-MSC CFU-F (colonies/mL) & BM-MSC expansion & 372.5 & 287.5 & 155 & 47.5 \\
\hline $\begin{array}{l}\text { BM-MSC seeding density (cells/ } \\
\mathrm{cm}^{2} \text { ) }\end{array}$ & BM-MSC harvest & 8.51 & 6.57 & 2.66 & 0.81 \\
\hline Harvest yield (cells $/ \mathrm{cm}^{2}$ ) & BM-MSC harvest & $4.78 \mathrm{E}+04$ & $4.01 \mathrm{E}+04$ & $5.31 \mathrm{E}+04$ & $4.04 \mathrm{E}+04$ \\
\hline Harvest yield (viable cells) & BM-MSC harvest & $2.51 \mathrm{E}+07$ & $2.10 \mathrm{E}+07$ & $2.79 \mathrm{E}+07$ & $2.12 \mathrm{E}+07$ \\
\hline BM-MSC membrane integrity (\%) & BM-MSC harvest & 97.7 & 96 & 98.6 & 98.1 \\
\hline Population doublings & BM-MSC harvest & 12.45 & 12.57 & 14.28 & 15.59 \\
\hline Doubling time $(\mathrm{h})$ & BM-MSC harvest & 23.13 & 22.92 & 25.21 & 23.09 \\
\hline
\end{tabular}

Table 5

Verification of BM-MSC cryopreservation, post-thaw expansion and quality attributes.

\begin{tabular}{|c|c|c|c|c|c|}
\hline \multirow[b]{2}{*}{ Parameter } & \multirow[b]{2}{*}{ Process stage } & \multicolumn{4}{|c|}{ Donor ID (verification runs) } \\
\hline & & LOC18 003 & LOC18 004 & LOC18 005 & LOC18 006 \\
\hline Culture medium & BM-MSC expansion & DMEM + $10 \%$ Stemulate HPL & DMEM + 10\% Stemulate HPL & DMEM + 10\% Stemulate HPL & DMEM + 10\% Stemulate HPL \\
\hline BM-MSCs (cells/vial) & Cryopreservation & $1.00 \mathrm{E}+06$ & $1.00 \mathrm{E}+06$ & $2.00 \mathrm{E}+06$ & $1.00 \mathrm{E}+06$ \\
\hline DMSO (\%) & Cryopreservation & $1.00 \mathrm{E}+01$ & $1.00 \mathrm{E}+01$ & $1.00 \mathrm{E}+01$ & $1.00 \mathrm{E}+01$ \\
\hline Cooling rate $\left(-{ }^{\circ} \mathrm{C} / \mathrm{min}\right)$ & Cryopreservation & 1 & 1 & 1 & 1 \\
\hline Vials & Cryopreservation & 1 & 1 & 1 & 1 \\
\hline BM-MSCs (cells/vial) & Post-thaw & $9.10 \mathrm{E}+05$ & $8.26 \mathrm{E}+05$ & $1.78 \mathrm{E}+06$ & $9.14 \mathrm{E}+05$ \\
\hline $\begin{array}{l}\text { BM-MSC membrane integ- } \\
\text { rity (\%) }\end{array}$ & Post-thaw & 85.18 & 78.90 & 88.43 & 88.59 \\
\hline Viable cell recovery (\%) & Post-thaw & $7.75 \mathrm{E}-01$ & $6.52 \mathrm{E}-01$ & 7.87E-01 & $8.10 \mathrm{E}-01$ \\
\hline P1 culture duration (days) & Post-thaw outgrowth & 4 & 4 & 4 & 4 \\
\hline Culture medium & Post-thaw outgrowth & DMEM + 10\% Stemulate HPL & DMEM + $10 \%$ Stemulate HPL & DMEM + 10\% Stemulate HPL & DMEM + 10\% Stemulate HPL \\
\hline Feeding strategy & Post-thaw outgrowth & Fed d 2 & Fed d 2 & Fed d 2 & Fed d 2 \\
\hline Population doublings & Post-thaw harvest & 3.02 & 3.40 & 3.21 & 3.21 \\
\hline Doubling time $(\mathrm{hr})$ & Post-thaw harvest & 23.91 & 21.17 & 22.56 & 22.45 \\
\hline $\begin{array}{l}\text { Cell-specific glucose con- } \\
\text { sumption (pmo/cell. } \\
\text { day }^{-1} \text { ) }\end{array}$ & Post-thaw outgrowth & 26.88 & 16.00 & 21.88 & 21.85 \\
\hline $\begin{array}{l}\text { Cell-specific lactate produc- } \\
\left.\text { tion (pmol/cell.day }{ }^{-1}\right)\end{array}$ & Post-thaw outgrowth & 57.46 & 39.11 & 39.46 & 51.70 \\
\hline qLactate/qGlucose & Post-thaw outgrowth & 2.14 & 2.44 & 1.80 & 2.37 \\
\hline $\begin{array}{l}\text { Cell-specific ammonia pro- } \\
\left.\text { duction ( } \mathrm{pmol} / \text { cell.day }^{-1}\right)\end{array}$ & Post-thaw outgrowth & 9.99 & 8.74 & 10.50 & 15.02 \\
\hline $\begin{array}{l}\text { BM-MSC membrane integ- } \\
\text { rity (\%) }\end{array}$ & Post-thaw harvest & 99.23 & 99.25 & 99.33 & 98.90 \\
\hline CD90 (FITC) (\%) & Post-thaw harvest & 99.80 & 99.95 & 99.95 & 99.95 \\
\hline CD105 (PerCP-Cy $\left.{ }^{\mathrm{TM}} 5.5\right)(\%)$ & Post-thaw harvest & 99.65 & 99.65 & 99.45 & 99.45 \\
\hline CD73 (APC) (\%) & Post-thaw harvest & 99.90 & 99.90 & 99.90 & 99.90 \\
\hline $\begin{array}{l}\text { CD } 45 / C D 34 / C D 11 b / C D 19 / \\
\text { HLA-DR (PE) (\%) }\end{array}$ & Post-thaw harvest & 0.11 & 0.02 & 0.11 & 0.01 \\
\hline CD44 (PE) $(\%)$ & Post-thaw harvest & 99.80 & 99.90 & 99.90 & 99.90 \\
\hline SSEA-4 (PE) (\%) & Post-thaw harvest & 55.80 & 48.39 & 36.66 & 45.65 \\
\hline $\begin{array}{l}\text { CD106 (VCAM) (PerCP- } \\
\left.\text { Cy }^{\mathrm{TM}} 5.5\right)(\%)\end{array}$ & Post-thaw harvest & 3.26 & 2.67 & 21.96 & 16.85 \\
\hline CD146 (MCAM) (APC) (\%) & Post-thaw harvest & 95.33 & 94.14 & 94.90 & 89.60 \\
\hline VEGF (fg/cell.day ${ }^{-1}$ ) & Post-thaw harvest & 13.57 & 5.79 & 5.62 & 6.25 \\
\hline $\begin{array}{l}\text { Osteogenic differentiation } \\
\text { (alizarin red stained) }\end{array}$ & Post-differentiation & Pass & Pass & Pass & Pass \\
\hline
\end{tabular}


many patients could be served by a manufacturing facility under the current state of the art. Such a model provides insight into how culture duration can vary dramatically over many days between patients with MSC-rich marrow aspirate, versus those with MSC-poor marrow. Appreciating these timing issues allows mitigating strategies to be identified and deployed, for example, introducing automation to manage flask incubation and non-invasive inspection with whole flask microscopy to determine when to harvest. The option to perform passaging and additional culture period may also be adopted in the small number of cases where a therapeutic dose is not realized in a timely manner, or where there exist concerns about a critical quality attribute that requires sampling of cells.

A further observation is the logistical usefulness of fixed aspirate volume and surface area for seeding, rather than seeding cells to a target cell density (cells/mL or cells $/ \mathrm{cm}^{2}$ ). Seeding large volumes based on mononuclear cell density is commonly used where the end goal is to maximize the number of hBM-MSCs obtained from a donor [21,22]. Because isolated cell density (and percentage of stem cells within) varies by orders of magnitude, the total surface area seeded (and, therefore, the number of flasks) will also correspondingly vary. Sampling, cell counting, dilution factor calculation, bone marrow aspirate dilution, flask number determination and acquisition and sequential flask seeding are all required to achieve a target seeding density. Fixed surface seeding simplifies processing because cell counts are no longer essential and minimal calculations are required by operators. Fewer manual liquid handling steps are needed, which minimizes contamination risk and scope for operator error. Fixing surface area also means standardizing flask dimension, flask number and medium requirement for each donor, simplifying resource management and cost of goods analysis. The only requirement is definition of the maximum cell yield as a function of surface area, which can then be adjusted to provide overage for robustness in cases where more stem cells are isolated than average. In our case, we predict a minimum of $400 \mathrm{~cm}^{2}$ would satisfy a 2E7 cell harvest target, assuming $5 E 4$ cells $/ \mathrm{cm}^{2}$, a single $500 \mathrm{~cm}^{2}$ triple-layer flask or three T175 flasks $\left(525 \mathrm{~cm}^{2}\right)$.

The model framework can be built upon to incorporate other stochastic processes of relevance to bioprocessing outcomes, for example, decay of isolatable cell yield with different shipping methods (temperature control and duration) and disease-specific changes in cell yield and quality. Such a modelling approach can also be adjusted to account for different cell culture systems, where doubling time differs as a result of growth medium choice or other factors that influence culture behavior. A common example would be where human serum is used to culture hBM-MSCS, rather than HPL. If serum was to be used without pre-screening, it is probable that some serum lots would result in increased frequency of inadequate proliferation rates and, therefore, more frequent failure to achieve cell targets within a defined manufacturing window. Using HPL instead of serum was principally to minimize the risk of inter-donor consistency accentuated by lot-specific differences [23]. Other factors, including oxygen tension relating to the atmospheric oxygen concentration, may also accentuate inter-donor differences in proliferation rates. Our use of $4 \%$ atmospheric oxygen concentration for hBM-MSC incubation was based on several studies linked to relative proliferative enhancement under these conditions compared with normal atmospheric oxygen concentration of $20 \%[24,25]$. Any process differences such as these would require re-specification of the model to determine acceptable operating parameters given the resultant performance distributions.

Similarly, although four engineering runs is not enough to confidently define the real distribution of growth rate variation, manufacturing criteria could be modified, if necessary, using the same model as further population data was collected. If a patient group had specific performance attributes, these would emerge and allow modification of the model and process over time. A good data collection and monitoring plan through product development would be a critical part of a quality risk management strategy and essential to strengthen the model and feed modifications; an obvious area for development would be a database linking critical quality attributes and clinical outcomes to total proliferation and terminal harvest densities; once sufficient data exists to determine the clinical effect of cells that have undergone different culture profiles, a more informed approach can be taken to selecting aspirate volume given the quality risk of under- or over-confluence at harvest. Such data would also help establish which of the donors that exceed the established window may still be clinically applied, an important consideration given the value of autologous material. It could also be used to track performance of individual clinical centers and clinical approaches, thereby aiding training, dissemination of best practice and reduction in donor site variability; this is a particularly important consideration given the reduced frequency of bone marrow aspirations and possible loss of skills.

A potential limitation of this study is that the statistical distributions used in the modelling were obtained from a single source, comprising 30 individual donors. Limited richness of the underlying data forces simplification (assuming a normal distribution) and a conservative approach when assuming appropriate parameters for the construction of each probability distribution. These assumptions influence the model output and, subsequently, the estimation of the failure rate used to define acceptable bioprocess parameter setpoints, as well as raw materials and consumables used for cell expansion. It is likely the model underestimates or overestimates the real risk of batch failure. Overestimation is preferable, as a degree of robustness will be built into the resulting bioprocess by default, but has an economic cost implication. Underestimation would mean accepting a bioprocess that may fail to meet cell expansion target within a defined expansion window. This would either require extending the manufacturing window with additional culture time and resource or a decrease in the operational capacity of a manufacturing facility impacting cost of goods.

Some hMSC therapies require larger doses $\left(>10^{8}\right.$ cells), which could require excessive population doublings to achieve depending on the quality of the input cell material. Because our framework accounts for population-level proliferation rate, scalability can be explored by changing target cell yield and evaluating the number of population doublings needed to achieve this target reliably. Increased risk of cell quality changes as population doubling target increases (e. g., $>30$ from healthy human donors), which means more aspirate volume will be required to achieve target within a reasonable manufacturing window. Consequently, our framework allows scaling questions to be appropriately defined early in development, which in turn allows informed dialogue from clinical sites about the operational feasibility and training requirements where, for example, multiple, smaller aspirations would be preferred to maintain aspirate quality.

In studies such as these assumptions are made to support a useful model within the limits of available data. For example, we assume that all cells within a population will be equally potent and make assumptions regarding effective therapeutic dosages. Isolation and expansion of sub-populations with ideal properties for a particular therapeutic indication are expected to alter effective therapeutic dosing as well as isolatable cell distribution. Diseased or impaired cells may suppress therapeutic modes of action, if present in sufficient proportions of a clinically relevant cell population. Such aspects could be incorporated into new models using the same broad approach as product knowledge improves.

Better quality data of cell isolation outcomes, whether it is from well-described patient populations, different isolation methods (e.g., gradient separations) and different biological origins, can all be used to make the model more informative of the real-world situation. In this way, a cell therapy developer can progressively obtain a richer data set over the development lifecycle from pre-clinical all the way 
through clinical trials to post-market approval and monitoring. This not only helps in refining bioprocess parameters to control the risk of batch failure within acceptable thresholds, but can also support discrimination and troubleshooting of potentially sub-optimal results within a network of distinct clinical sites as part of continual improvement of the staff performing the stem cell isolation procedures.

Ultimately, we show the Monte Carlo approach is a useful tool for process design and quality risk management of cell sourcing for cell therapy process development within the logistical constraints particular to this field. The bioprocess established here as an exemplar to highlight the model framework is suitable for a standardized cell expansion process for personalized cell therapies for a clinically challenging orthopedic indication where the ultimate goal is integration of manufactured cells with proprietary matrices to realize a celldevice combination product for use in bone fusion procedures. Finally, it recognizes that data will always be limited throughout development and establishing a framework that can continually incorporate new data to achieve best outcomes will be important in maximizing success of cell therapies in cases where cell yield during initial isolation can vary considerably.

\section{Funding}

This work was funded by LocateBio, as part of an award from InnovateUK, to adapt LocateBio's TAOS technology (Targeted, Orchestrated Signalling Matrix) for use in administering therapeutic cells.

\section{Declaration of Competing Interest}

The authors have no commercial, proprietary, or financial interest in the products or companies described in this article.

\section{Author Contributions}

Conception and design of the study: APi, AI-M, LJ, APr, RQ, RT. Acquisition of data: APi, JH. Analysis and interpretation of data: APi, JH, RT. Drafting or revising the manuscript: APi, RT. All authors have approved the final article.

\section{References}

[1] Pittenger MF, Discher DE, Péault BM, Phinney DG, Hare JM, Caplan AI. Mesenchymal stem cell perspective: cell biology to clinical progress. NPJ Regenerative Medicine 2019;4:22

[2] Robbins MA, Haudenschild DR, Wegner AM, Klineberg EO. Stem Cells in Spinal Fusion. Global Spine Journal 2017;7(8):801-10.

[3] Perez JR, Kouroupis D, Li DJ, Best TM, Kaplan L, Correa D. Tissue Engineering and Cell-Based Therapies for Fractures and Bone Defects. Frontiers in Bioengineering and Biotechnology 2018;6:105.

[4] Skovrlj B, Guzman JZ, Al Maaieh M, Cho SK, Iatridis JC, Oureshi SA. Cellular bone matrices: viable stem cell-containing bone graft substitutes. Spine Journal 2014;14(11):2763-72.
[5] Krueger TE, Thorek DL, Denmeade SR, Isaacs JT, Brennen WN. Concise Review: Mesenchymal Stem Cell-Based Drug Delivery: The Good, the Bad, the Ugly, and the Promise. STEM CELLS Translational Medicine 2018;7:651-63.

[6] Lohan P, Treacy O, Griffin MD, Ritter T, Ryan AE. Anti-Donor Immune Response Elicited by Allogenic Mesenchymal Stem Cells and Their Extracellular Vesicles: Are We Still Learning? Frontiers in Immunology 2017;8:1626.

[7] Berglund AK, Fortier LA, Antczak DF, Schnabel LV. Immunoprivileged no more: measuring the immunogenicity of allogeneic adult mesenchymal stem cells. Stem Cell Research \& Therapy 2017;8:288.

[8] Lohan P, Coleman CM, Murphy JM, Griffin MD, Ritter T, Ryan AE. Changes in immunological profile of allogenic mesenchymal stem cells after differentiation: should we be concerned? Stem Cell Research \& Therapy 2014;5:99.

[9] Galipeau J, Sensebe L. Mesenchymal Stromal Cells: Clinical Challenges and Therapeutic Opportunities. Cell Stem Cell 2018;22:824-33.

[10] Lopez F, Di Bartolo C, Piazza T, Passannanti A, Gerlach JC, Gridelli B, Triolo F. A Quality Risk Management Model Approach for Cell Therapy Manufacturing. Risk Analysis 2010;30:1857-71

[11] Lipsitz YY, Timmins NE, Zandstra PW. Quality cell therapy manufacturing by design. Nature Biotechnology 2016;34:393-400.

[12] Siegel G, Kluba T, Hermanutz-Klein U, Bieback Northoff, N, Schäfer R. Phenotype, donor age and gender affect function of human bone marrow-derived mesenchymal stromal cells. BMC Medicine 2013;11:146.

[13] Fadini GP, Ferraro F, Quaini F, Asahara T, Madeddu P. Concise review: diabetes, the bone marrow niche, and impaired vascular regeneration. Stem cells translational medicine 2014;3(8):949-57

[14] Vanhelleputte P, Nijs K, Delforge M, Evers G, Vanderschuerern S. Pain during bone marrow aspiration: prevalence and prevention. Journal of Pain and Symptom Management 2003;26(3):860-6.

[15] Hernigou P, Homma Y, Lachaniette CHF, Poignard A, Allain J, Chevallier N, Rouard $\mathrm{H}$. Benefits of small syringe for bone marrow aspirations of mesenchymal stem cells. International Orthopaedics 2013;37(11):2279-87.

[16] Hahn S, Sireis W, Hourfar K, Karpova D, Dauber K, Kempf VAJ, Seifried E, Schmidt M, Bönig H. Effects of storage temperature on hematopoietic stability and microbial safety of BM aspirates. Stem Cell Procurement 2013;49:338-48.

[17] Dominici DM, Le Blanc K, Mueller I, Slaper-Cortenbach I, Marini F, Krause D, Deans RJ, Keating A, Prockop DJ, Horwitz EM. Minimal criteria for defining multipotent mesenchymal stromal cells. The International Society for Cellular Therapy position statement. Cytotherapy 2006;8:315-7.

[18] Heathman TRJ, Rafiq QA, Chan AKC, Coopman K, Nienow AW, Kara B, Hewitt CJ Characterization of human mesenchymal stem cells from multiple donors and the implications for large scale bioprocess development. Biochem Eng J 2016;108: $14-23$.

[19] Hanga MP, Murasiewicz H, Pacek AW, Nienow AW, Coopman K, Hewitt CJ. Expansion of bone marrow-derived human mesenchymal stem/stromal cells (hMSCs) using a two-phase liquid/liquid system. Journal of Chemical Technology and Biotechnology 2017;92(7):1577-89.

[20] Boregowda S, Phinney DG. Quantifiable Metrics for Predicting MSC Therapeutic Efficacy. Journal of Stem Cell Research \& Therapy 2017;6(11):365.

[21] Fekete N, Rojewski MT, Fürst D, Kreja L, Ignatius A, Dausend J, Schrezenmeier H. GMP-Compliant Isolation and Large-Scale Expansion of Bone Marrow-Derived MSC. PLOS One 2012;7(8):e43255.

[22] Lechanteur C, Briquet A, Giet O, Delloye O, Baudoux E, Beguin Y. Clinical-scale expansion of mesenchymal stromal cells: a large banking experience. Journal of Translational Medicine 2016;14:145.

[23] Heathman TR, Stolzing A, Fabian C, Rafiq QA, Coopman K, Nienow AW, Kara B, Hewitt CJ. Scalability and process transfer of mesenchymal stromal cell production from monolayer to microcarrier culture using human platelet lysate. Cytotherapy 2016;18:523-35.

[24] Grayson WL, Zhao F, Bunnell B, Ma T. Hypoxia enhances proliferation and tissue formation of human mesenchymal stem cells. Biochem Biophys Res Commun 2007;358:948-53.

[25] Das R, Jahr H, van Osch GJ, Farrell E. The role of hypoxia in bone marrow-derived mesenchymal stem cells: considerations for regenerative medicine approaches. Tissue Eng Part B Rev 2010;16:159-68. 